Artigos/Articles

\title{
O corpo na elaboração Saussuriana do conceito de língua: um ponto paradoxal ${ }^{1}$ \\ The body in the Saussurian elaboration of the concept of language: a paradoxical point
}

Glória Maria Monteiro Carvalho²

\section{RESUMO}

Neste artigo, proponho-me colocar em discussão o lugar ocupado pela noção de corpo do falante na concepção saussuriana de língua como sistema. Filio-me à proposta de vários linguistas, segundo a qual, ao longo do percurso de elaboração do conceito saussuriano de signo, as oscilações e ambiguidades terminológicas, até chegar aos termos significante e significado, consistem em uma tentativa do genebrino de excluir do signo qualquer vestígio de substancialidade sonora ou conceitual. Dando destaque ao significante, assumo a proposta de que a tentativa de excluir, do conceito de signo, qualquer resquício de som significa uma tentativa de excluir, desse conceito, o corpo do falante. O corpo excluído, entretanto, retornaria à formulação da língua como sistema na forma de paradoxos, alguns dos quais pretendi abordar, realçando aqueles que podem ser indicados no CLG.

Palavras-chave: Saussure; corpo; som; sistema da língua; paradoxos.

1. Este artigo faz parte da execução de Projeto de Pesquisa financiado pelo CNPq. E-mail: gloria.carvalho@pesquisador.cnpq.br.

2. Programa de Pós-graduação em Ciências da Linguagem da Universidade Católica de Pernambuco - UNICAP - Pernambuco - Brasil. https://orcid.org.0000-0003-0595-1764. E-mail: gmmcarvalho@uol.com.br. 


\begin{abstract}
In this article, I propose to put in discussion the place occupied by the notion of the speaker's body in the Saussurean conception of language as a system. I join the proposal of several linguists, according to which, throughout the course of elaborating the Saussurean concept of sign, the terminological oscillations and ambiguities, until arriving at the terms signifier and signified, consist of an attempt of Genevan to exclude from the sign any trace of sound or conceptual substantiality. By pointing out the signifier, I take up the proposition that the attempt to exclude any trace of sound from the concept of a sign implies an attempt to exclude the body of the speaker from this concept. The excluded body, however, would return to the formulation of language as a system in the form of paradoxes, some of which I intended to address, highlighting those ones that may be indicated in the CLG.
\end{abstract}

Keywords: Saussure; body; sound; language system; paradoxes.

\title{
Introdução
}

Pretendo, neste artigo, dar continuidade a trabalhos anteriores (CARVALHO, 2016a; 2016b), em que abordo a questão do corpo em Saussure a partir da seguinte questão: qual o lugar ocupado pelo corpo do falante na concepção saussuriana de signo?

Retomarei, portanto, essa questão, na tentativa de formular outras indagações no que diz respeito à noção saussuriana de corpo, recorrendo, basicamente, a extratos dos manuscritos de Genebra contidos nos Escritos de Linguística Geral (2004) - daqui por diante, ELG -, a extratos dos manuscritos de Harvard reunidos e publicados por Parret nos Cahiers Ferdinand de Saussure (1993), ao Curso de Linguística Geral (Saussure, [1916] 1989) - daqui por diante, CLG -, a textos de Parret (2011, 2013), de Milner (O amor da língua, 2012) e de Starobinski (As palavras sob as palavras, 1974).

Já nos trabalhos referidos, filiei-me à proposta de vários autores, como Arrivé (2010), De Mauro (1985), Depecker (2012), Parret (2009), para quem a constante substituição de um termo por outro, em relação a cada uma das faces do signo, não constitui um movimento fortuito. 
Dizendo de outro modo, durante a elaboração saussuriana de signo, as ambiguidades, as oscilações terminológicas, até chegar aos termos: significante e significado, consistem em um movimento no sentido de excluir do signo qualquer vestígio de substancialidade (sonora ou conceitual).

Do signo saussuriano, recorto a imagem acústica, apontando para uma grande variedade de temos, como por exemplo: som, imagem verbal, imagem auditiva, impressão acústica (Depecker, 2012), signo vocal, sequência de sons, símbolo fonético (Bouquet, 2004), forma, para citar apenas alguns, sem seguir sua ordem de aparecimento.

Convém realçar que, neste momento, assumo a proposta de que a tentativa de excluir, do conceito de signo, qualquer resquício de som significa uma tentativa de excluir, desse conceito, o corpo do falante. No entanto, assumo também que essa exclusão não ocorreria sem consequências. Nessa perspectiva, o corpo excluído retornaria à formulação do signo saussuriano - ou, mais amplamente, à formulação da língua como sistema - na forma de paradoxos, alguns dos quais pretendo, aqui, abordar.

\section{A questão do corpo na perspectiva saussuriana: o "julgamento do ouvido"}

A fim de iniciar a discussão, transcrevo o seguinte fragmento dos Manuscritos de Harvard, no item em que Saussure aborda a questão do fonema: "O ouvido só pode naturalmente decidir semelhanças, identidades e diferenças das percepções, mas suas causas que estão na dependência mútua ou podem (sic) ser supostas ser ali... (ilegível)". (Parret 1993: 202, fragmento 32, tradução minha).

Realço, então, a atividade do ouvido - denominada por Parret $(2013 ; 2014)$ julgamento do ouvido - que consiste em decidir sobre as identidades, semelhanças e diferenças entre sons, por meio de uma atividade de comparação (entre) e abstração de momentos acústicos simples. Nessa perspectiva, os sons afetam o ouvido, provocando essa atividade de decisão ou, em outras palavras, o som impressiona o ou- 
vido. No fragmento 33 (Manuscritos de Harvard), Saussure relaciona o método (da linguística) à impressão acústica:

Método que consiste, partindo da impressão acústica, em fixar/recolher os tempos fisiológicos tendo um interesse direto pela fonética. Depois procurar os caracteres intrínsecos desses tempos fisiológicos a fim de poder defini-los diretamente e se libertar de tempos em tempos do elemento empírico que .... (interrompido). (Parret 1993: 202, fragmento 33, tradução minha)

Destaco, nesse fragmento, a importância da impressão acústica como um ponto de partida que, entretanto, não consistiria em simples sensações, mas em uma atividade sobre elas, ou melhor, consistiria em sensações perceptíveis em que o ouvido relaciona sons idênticos.

Nessa direção, coloca o autor, nos manuscritos de Genebra (ELG):

É imediatamente visível que as entidades da ordem vocal ou consistem na identidade que acabamos de considerar, por conseguinte num fato perfeitamente abstrato, ou em nada consistem e não estão em parte alguma.

Continuando, dá um exemplo:

O fato, por exemplo, de aka ser pronunciado por uma pessoa, num certo lugar e num certo momento, ou o fato de mil pessoas, em mil lugares e em mil momentos, emitirem a sucessão de sons $a k a$, é, absolutamente, o único fato dado: mas não é menos verdade que só o fato ABSTRATO, a identidade acústica desses aka forma sozinha a entidade acústica aka: e não há um objeto primeiro a ser procurado, mais tangível do que esse primeiro objeto abstrato. (Saussure 2004: 33, Sobre a essência dupla da linguagem-Acervo BPU, 1996, extrato do fragmento 5b, § 2)

Desse modo, a escuta da identidade de sons seria o ponto de partida, a condição do método (do linguista), ou seja, a identidade acústica dos aka forma a entidade acústica aka. Em outras palavras, a escuta da identidade de sons seria ponto de partida para a elaboração da língua como sistema.

Assim, dos extratos recortados, pode-se inferir que a entidade acústica seria produto da atividade do ouvido ao decidir sobre iden- 
tidades (semelhanças e diferenças) sonoras. Por sua vez, esse ponto de partida (esse objeto primeiro), essa condição é, ao mesmo tempo, concreto (tangível) e abstrato, na medida em que "não há um objeto primeiro a ser procurado, mais tangível do que esse primeiro objeto abstrato". Talvez não se deva abordar essa relação entre contrários como uma contradição - já que são tantas as contradições, as hesitações, os enigmas detectados nos textos saussurianos - mas, como um terceiro assumido por Saussure. Segundo os requisitos da lógica clássica ${ }^{3}$, um dos contrários deveria ser excluído pelo ou disjuntivo: ou é concreto (tangível) ou é abstrato, não se admitindo uma terceira possibilidade, isto é, a combinação pelo conjuntivo $e$ - concreto e abstrato - sendo, portanto, excluída essa conjunção.

A atividade decisória do ouvido deixa mais visível também a conjunção do corpóreo e do incorpóreo. A esse respeito, Saussure, numa passagem do ELG, refere-se ao som e, ao mesmo tempo, a uma oposição entre sons, considerando-a como a "primeira aplicação rudimentar, mas já incontestável, do princípio das OPOSIÇÕES, ou dos VALORES RECIPROCOS, ou das QUANTIDADES NEGATIVAS e RELATIVAS que criam um estado da língua. (Saussure 2004: 27, Sobre a essência dupla da linguagem - Acervo BPU, 1996, extrato do fragmento $3 \mathrm{c}$, ênfase minha), indicando, portanto, o som, ou melhor, o corpo-ouvido como fundamento do valor.

Sobre a conjunção mencionada, vale ainda colocar outra passagem do ELG:

Natureza incorpórea, como para todo valor, daquilo que faz as unidades da língua. Não é matéria fônica, substância vocal que [...]. Não se pode tratar um instante a língua sem se ocupar do som e dos sons, a mudança dos sons é um fator capital, e isso não impede que, num certo sentido, o som seja estranho à natureza, etc. (Saussure 2004: 247, Notas preparatórias para os Cursos de Linguística Geral. Novos documentos - Acervo BPU, 1996, extrato do fragmento 1)

Assim, a concepção de corpo-ouvido em Saussure consiste em um terceiro, provocando uma ruptura em um dos princípios básicos (o princípio do terceiro excluído) da lógica clássica, isto é, rompendo com 
a relação de exclusão entre contrários, como por exemplo: concretoabstrato, corpóreo-incorpóreo, objetivo-subjetivo, ativo-passivo. Em relação a esse último par, o ouvido, como receptor, é passivo, mas como "ouvido que julga", é ativo; do mesmo modo, há uma objetividade na recepção de sons, mas uma subjetividade na atividade de decidir.

\section{Condição para o advento do sistema da língua: expulsão vs recalque do corpo-ouvido}

Segundo Parret (2011), na elaboração saussuriana, o corpo está na voz, entre a boca e o ouvido. Diz ele: "A expulsão do corpo em um Para fora impensável, irrecuperável é a condição sine qua non do triunfo do Método, da ciência a advir [...]" (2011: 8, tradução minha)

Assumo, entretanto, que, como fundamento, como condição do diferencial da língua concebida como sistema de valores, o corpoouvido não poderia ser expulso, excluído, eliminado. Ele poderia (ou deveria) ser recalcado (no sentido psicanalítico) ${ }^{4}$ em favor do surgimento desse sistema.

Convém notar que Parret se refere tanto à expulsão do corpo em caráter irrecuperável (2011) como a recalque do corpo (2013). A partir da proposta de uma intimidade fugidia ${ }^{5}$ em Saussure formulada por Normand (apud Parret, 2013), aquele autor afirma: "Se há tantos 'brancos' na teoria da cadeia sonora é que a negação da voz repousa no recalcamento do corpo-feito-voz" (Parret, 2013:14-15, tradução e ênfase minhas). Mas, acrescenta, logo em seguida: "Não tenho a menor intenção de fazer emergir o inconsciente saussuriano e, apenas, destaco, sem dramatização, algumas sequências a propósito do corpo-feito-voz, fontes do estrito Método". (2013:15, tradução minha). Assume, então, a hipótese formulada por Normand a qual é, por ele, colocada nos seguintes termos: "é que esses 'brancos' mostram que não é fácil, nem

4. Do ponto de vista psicanalítico, o recalque consiste no "processo de afastamento das pulsões às quais é rejeitado o acesso à consciência." (Chemama, 1995 : 185). Por sua vez, o retorno daquilo que fora recalcado constitui a outra face desse processo, "pois o recalcado retorna a seu lugar de origem, o simbólico, no qual havia sido primitivamente admitido." (Chemama, 1995: 80) 
mesmo possível, expulsar da reflexão teórica o som da voz, o gesto da mão a presença insistente do corpo. A existência do branco remete [...] ao corpo feito voz." (2013: 2). Assim, embora admita a expulsão em caráter irrecuperável do corpo-feito-voz, admite, nesses brancos, a presença insistente do corpo, a presença insistente de efeitos de verdade, ou de efeitos de uma intimidade fugidia.

Considerando que o recalque (do ponto de vista psicanalítico) implica o retorno do recalcado, como sua outra face, supomos que, em alguns lugares da elaboração saussuriana, além desses brancos, podem ser indicados vestígios do recalque do corpo e, portanto, de seu retorno. Sugiro, então, três desses lugares: 1) Um retorno do corpo no próprio percurso da elaboração saussuriana de signo ou, de um modo mais geral, no percurso de elaboração da língua como sistema; 2) Um retorno do corpo nos anagramas; 3) Um retorno do corpo no CLG.

\section{O retorno do corpo em alguns lugares da elaboração saussuriana: a emergência de paradoxos}

Em relação ao primeiro lugar sugerido e com fundamento no que foi posto, anteriormente, neste artigo, diria que, no percurso de elaboração do signo saussuriano, um indício de retorno do corpo pode ser localizado por meio de um paradoxo formulado nos seguintes termos: de um lado, o corpo, como um terceiro, é condição para o surgimento do diferencial da língua e, de outro lado, o corpo rompe, desfaz esse diferencial.

Em relação aos anagramas saussurianos, recorro a Milner (2012), por meio de duas afirmações desse autor:

- "o anagrama, a bem dizer, renega o signo saussuriano". (2012: 86)

- "o anagrama afronta o próprio princípio de todas as descrições linguísticas ou gramaticais: quaisquer que sejam seus métodos, estes supõem o terceiro excluído" (2012: 87), destacando então, no anagrama, seu caráter de terceiro. 
É importante notar, conforme adverte Starobinski (1974: 34), que "o anagrama, em vez de se referir ao arranjo espacial das letras, refere-se aos fonemas, à dicção da palavra-tema [...]" cuja escuta se desenvolve segundo um outro tempo, isto é, saímos do tempo da consecutividade próprio à linguagem habitual. Saussure (in Starobinski, 1974), ao colocar em discussão o princípio do dífono, nos anagramas, afirma: "Pode-se dar TAE por $t a+t e$, isto é, convidar o leitor não mais a uma justaposição na consecutividde, mas a uma média das impressões acústicas fora do tempo?" (1974: 35). Nessa citação, destaco a expressão "média das impressões acústicas fora do tempo".

Pergunto então: esse fora do tempo, esse tempo outro não seria o tempo da retroação, do só-depois?

É importante realçar que a escuta dos anagramas, segundo Milner (2012), implica a escuta da homofonia a qual tangencia um real (na concepção lacaniana do termo), o real da língua ${ }^{6}$.

Assim, a escuta das identidades ou semelhanças (e diferenças) sonoras entre a palavra-tema e as unidades do verso, ou melhor, a escuta da palavra-tema sob as palavras que compõem o verso, implica um efeito retroativo, efeito de só-depois. Segundo Starobinsky (1974: 33), trata-se de "juntar as sílabas diretrizes, como Isis reunia o corpo despedaçado de Osiris". Somente após a leitura do (s) verso (s), os fonemas/morfemas que constituem a palavra-tema - e que se encontram distribuídas ao longo do verso - podem se aglutinar/se amalgamar em nossa escuta.

Desse modo, o retorno do corpo, na escuta saussuriana dos anagramas, significa uma escuta da homofonia concebida como um terceiro excluído (da lógica clássica) que, ao romper o tempo consecutivo, tempo da linearidade do significante, instala-se em um outro tempo: o da retroação, do só depois.

Indago ainda: a escuta saussuriana dos anagramas não estaria apontando para um retorno do corpo-ouvido, como um terceiro que

6. A partir da proposta lacaniana, Milner (2012: 69) destaca, no conceito de real da língua, o "impossível de dizer". 
precisou ser excluído/recalcado ${ }^{7}$ para dar lugar ao signo, mais especificamente, ao valor linguístico?

Nessa perspectiva, também nos anagramas, pode-se sugerir, em relação ao retorno do corpo, um ponto paradoxal, isto é: a escuta da cadeia de significantes é condição para a escuta da palavra-tema a qual, entretanto, rompe a consecutividade temporal da cadeia.

Por sua vez, em relação ao CLG ([1916] 1989), o recalque do corpo (ou o retorno desse recalcado) como um terceiro excluído, seria indicado também por meio de pontos (aparentemente) paradoxais com que se poderia confrontar em alguns lugares dessa obra. Um desses lugares, em que se poderia apontar para um retorno do corpo por meio da homofonia, consiste em tentativas do genebrino de delimitar a unidade linguística (nos capítulos II e III), o que implica grande complexidade segundo seu próprio testemunho. A partir da leitura desse capítulo, supõe-se então que a complexidade, as dificuldades e dilemas que marcam essas tentativas seriam, pelo menos em parte, decorrentes do obstáculo colocado pela homofonia. Vê-se, portanto, um Saussure mergulhado em um movimento na direção tanto de estabelecer a diferença entre palavra e unidade concreta da língua, como de definir o conceito de identidade por ele assumido e que seria compatível com a concepção sistêmica de língua. $\mathrm{O}$ autor deixa visível a referida complexidade na delimitação da unidade linguística, ao se deparar com exemplos de homofonia, como sijelaprends, perguntando como se pode cortar essa sequência. Coloca o autor que as duas únicas divisões (si je la prends e si je l'apprends) possíveis para sijelaprends "são determinadas pelo sentido que se dê a essas palavras" ([1916] 1989): 121). Assim, em relação ao problema/obstáculo que esses termos homofônicos colocam para a delimitação das unidades linguísticas, Saussure propõe uma saída por meio do sentido. No entanto, ao que parece, trata-se de uma saída circular, posto que, ao mesmo tempo em que requer um sentido

7. Convém notar que Milner (2012) não se refere a recalque, mas a forclusão desse terceiro e, portanto, a retorno do forcluído. No sentido psicanalítico, diferentemente do que ocorre no recalque, na forclusão, "o significante que foi rejeitado da ordem simbólica reaparece no real" (Chemama, 1995: 80). Desse modo, o que fora rejeitado não pode mais retornar ao lugar de onde havia sido excluído, enquanto que o recalcado retorna a seu lugar de origem: o simbólico. Convém destacar que não nos cabe, neste trabalho, levar adiante a concepção psicanalítica desses dois processos - o recalque e a forclusão -, mas, apenas, indicar que são diferentes, sobretudo em relação à maneira como retornam. 
prévio à delimitação das unidades linguísticas, tal sentido advém como efeito dessa delimitação.

Logo a seguir, afirma:

Para verificar o resultado dessa operação e certificar-me de que se trata de fato de uma unidade, é preciso que, ao comparar uma série de frases onde se encontre a mesma unidade, se possa, em cada caso separá-la do resto do contexto, comprovando que o sentido autoriza a delimitação. ([1916] 1989): 121)

Conforme se pode inferir, a verificação do resultado dessa operação de corte, ao que parece, deixa mais visível o tempo da retroação instaurado pela escuta da homofonia, rompendo a consecutividade temporal da cadeia. Em outras palavras, é preciso comparar a escuta de várias cadeias verbais, comparação que implica um retorno à unidade recortada, a fim de comprovar o acerto.

Por sua vez, ao procurar definir o conceito de identidade, Saussure ([1916] 1989: 126) afirma que "O mecanismo linguístico gira todo ele sobre identidades e diferenças, não sendo estas mais que a contraparte daquela" e fornece exemplos "fora da linguagem", como o exemplo dos dois expressos e o do traje:

Assim falamos de identidade a propósito de dois expressos 'Genebra-Paris, 8 hs 45 da noite', que partem com vinte e quatro horas de intervalo. Aos nossos olhos, é o mesmo expresso, e no entanto, provavelmente, locomotiva, vagões, pessoal, tudo é diferente. [...]

Oponhamos aos casos precedentes, o caso - assaz diferente - de um traje que me tivesse sido roubado e que eu reencontro na loja de um adeleiro. Tratase de uma entidade material que reside unicamente na substância inerte, o pano, o forro, os aviamentos etc. Um outro traje, por parecido que seja ao primeiro, não será o meu" ([1916] 1989: 126)

Afirma, então: "Mas a identidade linguística não é a do traje, é a do expresso ...". ([1916] 1989: 126). Trata-se, portanto da identidade do valor ou, em outras palavras, a identidade implicada na língua concebida como sistema.

No entanto, ao assumir a identidade do valor, Saussure ([1916] 1989) não teria se confrontado, nesse capítulo, com o problema colo- 
cado pela homofonia, ou melhor, não teria tirado as consequências da questão da identidade entre si je la prends e si je l'apprends. Convém realçar que, nesse caso, a identidade não seria a do valor, mas se aproximaria da identidade do traje, na medida em que se trata da identidade (semelhanças e diferenças) do material sonoro que impressiona o corpo-ouvido. Pergunto se essa identidade (a do traje) não estaria, em última análise, mostrando, com mais visibilidade, a atividade decisória do corpo. Em outras palavras, pergunto se, nesse lugar, não se trataria de um retorno do corpo-ouvido, como um terceiro que teria sido excluído/recalcado para dar lugar ao valor, à concepção de língua como sistema. E ainda: nesse retorno, o corpo não estaria oferecendo resistência a ser assimilado à identidade do valor?

Conforme se pode notar, essas indagações estariam enunciando um ponto paradoxal colocado pela questão da identidade da homofonia, na medida em que essa identidade quebra a consecutividade temporal da identidade do valor.

Para tornar mais visível essa quebra da consecutividade temporal pela escuta da homofonia, relembre-se o exemplo presente em nota de rodapé do CLG ([1916] 1989: 146), tendo em vista que essa nota não é de autoria de Saussure, mas dos organizadores do Curso: "Os músicos produzem as notas e os perdulários as gastam"».

No CLG, estão conceituados os dois tipos de relação que se estabelecem entre os termos da língua: as relações sintagmáticas e as relações associativas. Quanto a estas últimas, conforme está colocado, trata-se de grupos formados por associações mentais, criando, com isso, tantas séries associativas quantas relações diversas existam. Assim, um grupo associativo pode está fundado "no significado e na comunidade de imagens acústicas"; outros, porém, podem se fundar "apenas no significado" e outros ainda, "na simples comunidade das imagens acústicas" ". Sobre o último caso, vale recortar a advertência contida na referida nota:

8. Trata-se da tradução, para a edição brasileira, do enunciado francês: les musiciens produizent les sons et les grainitiers les vendent.

9. De Mauro ([1916] 1985), em nota, rebate a colocação de Gödel de que a série de associações fundadas sobre simples encontros fonemáticos é um acréscimo dos editores. Diz aquele autor: "Isto não é inteiramente exato: mesmo que os exemplos sejam dos editores, a ideia fundamental é de Saussure que, como mostram as fontes, afirmava: [...] Pode-se 
[...] sua existência, porém, é provada por uma categoria inferior de jogos de palavras que se funda em confusões absurdas que podem resultar do homônimo puro e simples, como quando se diz em francês: 'Les musiciens produizent les sons et les grainitiers les vendent'. ([1916] 1989: 146)

Assim, como se pode ver pelo exemplo dado, trata-se da emergência de uma homofonia implicada nos dois significantes que possuem a mesma forma (notas) - os músicos fazem as notas; os perdulários as gastam (gastam as notas) - cuja associação não se apoia no significado, havendo um efeito de sentido a posteriori à produção/escuta da cadeia. Em outras palavras, é necessário escutar a cadeia até o final, para retornar aos termos notas escutados antes e, nesse só depois, poder lhes atribuir significados diferentes. Convém notar que, segundo Saussure, trata-se de duas unidades materiais diferentes. Essa falta de apoio inicial no significado, no referido exemplo, torna-se mais clara, quando, na mesma nota de rodapé, faz-se a distinção entre esse tipo de associação e a associação entre as palavras francesas ergot e ergoter que "embora fortuita, se pode apoiar numa aproximação de ideias" que "do ponto de vista sincrônico, cai simplesmente na categoria ensinar : ensino" ([1916] 1989): 146, nota de rodapé), em que entram a forma e o significado. Assim, a associação entre ergot e ergoter $=$ "moer de pancadas" não se encaixa no critério apenas da forma, perdendo seu caráter de homofonia, em virtude da entrada do significado na própria aproximação entre os dois termos, isto é, no próprio critério de associação.

Desse modo, a escuta necessária, como pré-requisito à atribuição de um significado ao significante, implica a presença de um corpo (um corpo-ouvido) que deve ser recalcado em função do significado. No entanto, no momento da escuta da homofonia, no primeiro exemplo dado (notas), esse corpo retorna, deixando visível sua atividade de decidir sobre identidades, semelhanças e diferenças sonoras. A esse respeito, retomemos a citação, em parte, já colocada anteriormente: 
O mecanismo linguístico gira todo ele sobre identidades e diferenças, não sendo estas mais que a contraparte daquelas. O problema das identidades se encontra, pois, em toda parte; mas, por outro lado, ele se confunde parcialmente com o das identidades e das unidades, do qual não passa de uma complicação, aliás fecunda. (Saussure, [1916] 1989: 126)

A diferença, portanto, entre o tipo de associação (homofônica) destacado - considerado inferior - e os demais, consistiria no fato de que ele traz à luz a atividade do corpo - o que não acontece com os outros em que essa atividade teria sido esquecida, recalcada em favor do significado. Em outras palavras, por meio da escuta da homofonia, teria vindo à tona o corpo como um terceiro que havia sido excluído - para que o significado pudesse emergir - e que, nesse momento, retornaria, rompendo a consecutividade temporal, ou seja, instaurando um tempo outro: o tempo da retroação.

\section{Algumas palavras para finalizar}

Convém retomar a questão da homofonia presente em nota de rodapé do CLG ([1916] 1989: 146), homofonia que foi tratada, nesta discussão, como um indicador da presença de um paradoxo, nesse lugar da obra saussuriana, destacando-se a advertência contida em tal nota. A referida advertência, ou seja, a rejeição no que toca as associações segundo o critério (apenas) da forma, ao que tudo indica, aponta para um paradoxo/dilema que parece reeditar os paradoxos já colocados antes, podendo ser formulado nos seguintes termos: de um lado, o corpo, como um terceiro, é condição para o surgimento do significado e, de outro lado, o corpo rompe, desfaz esse significado.

Não parece demais realçar que, na perspectiva assumida neste artigo, o conceito de corpo, embora tendo adquirido o estatuto de recalcado, por sua impossibilidade de ser assimilado ao caráter sistêmico da língua, estaria retornando, em alguns lugares da obra saussuriana, sob a forma de paradoxos (de dilemas) no que toca a questão da homofonia. Pode-se dizer, então, que esse conceito, ou melhor, a homofonia se faria especialmente visível no CLG, por meio do paradoxo, isto é, por meio de indicações paradoxais do retorno de um recalcado que, nas palavras de Parret (2014), consiste em uma presença insistente do corpo. 
Para finalizar, destaco, porém, que não me refiro a paradoxos do ponto de vista negativo. Ao contrário, suponho que uma maneira de se abordar conceitos presentes na obra saussuriana (não só no CLG, mas em outras fontes), considerando sua produtividade, seria pela via da escuta do paradoxo em que esses conceitos estariam imersos. Em outras palavras, a produtividade do conceito saussuriano de corpo se daria pela via do paradoxo que o envolve do qual poderiam ser tiradas consequências para a investigação, em vários campos do saber, onde possuam relevância as questões que envolvem a língua e o sujeito.

\section{Referências}

ARRIVÉ, Michel. 2010. Em busca de Ferdinand de Saussure. Tradução de Marcos Marcionilo. São Paulo: Parábola Editorial.

BOUQUET, Simon. 2004. Introdução à leitura de Saussure. Tradução de Carlos A. L. Salum e Ana Lúcia Franco. São Paulo: Editora Cultrix.

CARVALHO, Glória Maria Monteiro de. 2016a. O conceito saussuriano de signo: questões e consequências. Trabalho apresentado no $I I$ Colóquio Internacional Ferdinand de Saussure: Publicação do CLG e Heranças. Universidade Federal do Rio Grande do Norte, Natal, Rio Grande do Norte.

CARVALHO, Glória Maria Monteiro de. 2016b. Notas sobre a questão da singularidade da fala da criança. Revista do Gel, n. 13, p. 79-90.

COSTA, Newton da. 1980. Ensaio sobre os fundamentos da lógica. São Paulo: Hucitec.

DEPECKER, Loïc. 2012. Compreender Saussure a partir dos manuscritos. Tradução de Maria Ferreira. São Paulo: Editora Cultrix.

MILNER, Jean-Claude. 2012. O amor da língua. Tradução de Paulo Sérgio de Souza Júnior, Cláudia Thereza Guimarães de Lemos e Maria Rita Salzano Moraes. Campinas: Editora da UNICAMP.

PARRET, Herman. 1993. Les manuscrits Saussureans de Harvard. Cahiers de Ferdinand de Saussure, n.47, p.179-234.

. 2011. Le fondement impensable de la théorie linguistique saussurienne. Actes Sémiotiques [on line], n.114. Disponível em: https://www.unilim.fr/actes-semiotiques/1865. Acesso em: 27/04/2019.

. 2013. L'intimité fuyante de Saussure: "La théorie de la chaîne sonore est une étude des plus [ ]" [Écrits, 241]. Congrès International 
100 ans avec Saussure, Université de Sao Paulo, 16-20 de setembro de 2013. Disponível em: http://www.hermanparret.be/media/recentarticles/258.pdf. Acesso em: 27/04/2019.

.2014. Le Son et l'Oreille: Six essais sur les manuscrits saussuriens de Harvard. Limoges: Lambert-Lucas.

SAUSSURE, Ferdinand de. [1916] 1985. Cours de linguistique générale. Edição crítica preparada por DE MAURO, Túlio. Paris: Payot.

[1916] 1989. Curso de linguística Geral. Tradução de Antônio Chelini, José Paulo Paes e Izidoro Blikstein. São Paulo: Editora Cultrix.

. 2012. Escritos de linguística geral. Organizados e editados por BOUQUET, Simon; ENGLER, Rudolf. Tradução de Carlos Augusto Leuba Salum e Ana Lúcia Franco. Petrópolis, RJ: Vozes.

STAROBINSKI, Jean. 1974. As palavras sob as palavras: Os anagramas de Ferdinand de Saussure. São Paulo: Editora Perspectiva.

Recebido em: 04/03/2017

Aprovado em: 02/10/2018 